\title{
VISUAL INSPECTION OF WATER LEAKAGE FROM GROUND PENETRATING RADAR RADARGRAM
}

\author{
Nurniesya Nabila Halimshah, Amalina Yusup, Zulkarnaini Mat Amin, Mimi Diana Ghazalli
}

Department of Geoinformation, Faculty of Geoinformation \& Real Estate, Univerisiti Teknologi Malaysia, 81310, Skudai, Johor,

niesyabella@yahoo.com, zulkarnaini@utm.my

KEY WORDS: Water leaks, GPR, Radargram.

\begin{abstract}
:
Water loss in town and suburban is currently a significant issue which reflect the performance of water supply management in Malaysia. Consequently, water supply distribution system has to be maintained in order to prevent shortage of water supply in an area. Various techniques for detecting a mains water leaks are available but mostly are time-consuming, disruptive and expensive. In this paper, the potential of Ground Penetrating Radar (GPR) as a non-destructive method to correctly and efficiently detect mains water leaks has been examined. Several experiments were designed and conducted to prove that GPR can be used as tool for water leakage detection. These include instrument validation test and soil compaction test to clarify the maximum dry density (MDD) of soil and simulation studies on water leakage at a test bed consisting of PVC pipe burying in sand to a depth of $40 \mathrm{~cm}$. Data from GPR detection are processed using the Reflex 2D software. Identification of water leakage was visually inspected from the anomalies in the radargram based on GPR reflection coefficients. The results have ascertained the capability and effectiveness of the GPR in detecting water leakage which could help avoiding difficulties with other leak detection methods.
\end{abstract}

\section{INTRODUCTION}

Numerous activities are undertaken particularly in construction and provision of underground infrastructure nowadays. These activities required precise and reliable monitoring service especially on water distribution system. The most practical domestic device of underground infrastructure is that by detecting water leakage in the distribution system. According to Hasnul and Normayasuria (2009), old and dilapidated asbestos cement (AC) pipes contributes to major physical loses of water leakage. Nonrevenue Water (NRW) is an indicator used by National Water Services Commission (Suruhanjaya Perkhidmatan Air Negara) (SPAN) to reflect the performance of water supply in Malaysia. The estimated level of NRW in 2010 was $18 \%$ in Penang to $55 \%$ in Pahang (http://www.span.gov.my).

Recently in The Star Online article published on Sunday, February 16, 2014 reported that Petaling Jaya folk have experienced a dry taps which is due to the pipe burst within the area. Thus, some precaution should be done for wellbeing of life applications. Furthermore, Malaysia is a country which experience monsoon season throughout the year with high density of rainfall catalysing the risk of landslides to certainly tragedy. Therefore, more significant scientific studies are necessary in order to monitor the vicinity of buried utilities for general public and environment safety but also the network itself. In addition, on March 17, 2014, the Mass Rapid Transit (MRT) project has cost up by another millions which is due to utility damage. The most significant effect from the previous damage towards Malaysia gives problem not only to water supply but also in transportation.

This destructive damage had generated a killing wave and swept everything along its path as our country development problem. It propagated across nearly RM172 millions where it affected the Selangor area.

Besides the destruction effects, there are several identified minor malfunction within underground pipe cable which are mostly generate electromagnetic wave for the time being. Although the underground utility is just a minor breakdown, it is still necessary to take an action before it becomes a serious matter to the country. Moreover, Malaysia is also barely to other disasters such as heavy rain during the monsoon season. The high density of water leakage in the pipe or drain is vastly catalysing the risk to inevitably disaster. Based on all the highlighted disaster events mentioned above, Malaysia undoubtedly requires a competent and dynamic system which is capable to induce underground displacement in long term. This water supply management damage did not occur silently but with precursors. 


\section{METHODS}

This section focus on the operational framework of each experiment starting with the soil compaction is performed to clarify the maximum dry density (MDD) of sand as sand is used in this study. The testing infrastructure system and equipment needed in this survey were also being reviewed. Then, test on GPR calibration was performed at the National Institute of Land and Survey (INSTUN). Details of testing procedure are discussed in the following sections.

\subsection{Soil Compaction}

Essentially, soil compaction is a planned and organized method to stabilize soil and improve their performance. In order to understand the environmental influence on soil compaction in the field, such as road, it is necessary to understand the compaction procedure and moisture-density relations. Soil compaction is conducted to clarify the MDD of sand. The test was carried out at the Geotechnical lab, Faculty of Civil Engineering, UTM. Figure 1 shows the equipment used in soil compaction.

The soil compaction procedure begin with $5 \mathrm{~kg}$ of air dried sand sample that passes through $20 \mathrm{~mm}$ sieve is prepared. The sample is mixed thoroughly with $2 \%$ mass of moisture over $5 \mathrm{~kg}$ of air dried sand to obtain a low value of water content. $\left(\frac{2}{100} \times 5000 g\right.$ water with soil thoroughly and adequately since inadequate mixing gives rise to variable test results. Then, the mould

with base plate is weighted to the nearest $1 \mathrm{~g}\left({ }^{m_{1}}\right)$. The internal dimension is measured to $0.1 \mathrm{~mm}$. The extension mould is attached to the mould assembly on a solid base. A quantity of the soil mixture is placed into the mould such that it occupied one third of the height of the mould body.

The rammer is dropped from a height of $300 \mathrm{~mm}$ above the soil in 27 blows as controlled by the guide tube. The blows are scattered uniformly over the surface and ensure that the rammer falls freely and is not blocked by soil in the guide tube. This steps are repetitive until the volume of soil is sufficient to fill the mould body, with the surface not more than $6 \mathrm{~mm}$ above the upper edge of the mould body. It is compulsory to control the total volume of soil compacted.

The extension is removed, the assess soil is strike off and surface of the compacted soil is levelled off carefully to the top of mould via the straightedge. Any coarse particle is replaced, removed in levelling process, by finer material from the sample, well pressed in. The soil and mould is weighted with base plate to the nearest $1 \mathrm{~g}\left(m_{2}\right)$. The compacted soil is detached from the mould and retained on the metal tray. The weight sample is taken. Dry the soil in an oven at $105{ }^{\circ} \mathrm{C}$ to $110^{\circ} \mathrm{C}$ for $16-24$ hours, the mass of soil is weighted when cool. A descriptive sample is taken to determine its water content. The experiment is repeated with three varying mass of moisture over $5 \mathrm{~kg}$ of air dried sand sample. (4\%, $6 \%$ and $8 \%$ mass of moisture). The remainder of each compacted sample could be used several times after progressively increasing the amount of water. The values of water content corresponding to each volume of compacted soil are determined and it becomes possible to plot dry density to moisture content. The bulk density of each compacted specimen is calculated using equation below:

The bulk density:

Volume of mould $(\mathrm{V})=1.000 \mathrm{E}-03 \mathrm{~m}^{3}$

$\rho_{b}=$ Mass of the soil / Volume of the soil $\left(\mathrm{Mg} / m^{3}\right.$ )

$\rho_{b}=\frac{m_{2}-m_{1}}{W}$

Where;

$m_{1}=$ Mass of mould + base $(\mathrm{g})$
$m_{2}=$ Mass of mould + base ${ }^{+}$Compacted soil (g)

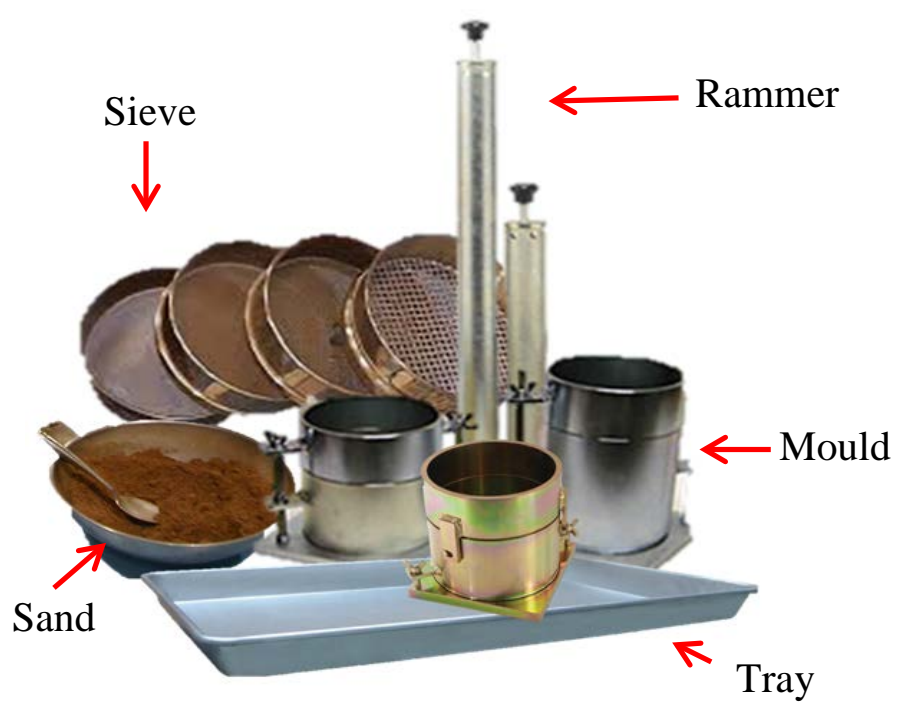

Figure 1. soil compaction equipment

\subsection{GPR Calibration}

GPR calibration was accomplished at the National Institute of Land and Survey (INSTUN), Ministry of Natural Resources and Environment, Behrang Ulu, Tanjung Malim, Perak on 19 October 2014 (see Figure 2). The utility mapping testing area has been planted with different kinds of cables and pipes. The GPR observation was carried out as shown by the arrow's direction. The plan view of the test base can be seen in Figure 3 with its detail as in Table 1 including the utility and material types. Therefore, the dissimilar bouncing waves at the image shows different types of pipe with diverse depth planted in the ground. The emitted waves contain varies elements of electricity, mainly the properties of dielectric and conductive constituents, magnetic permeability and physical properties of the object. 


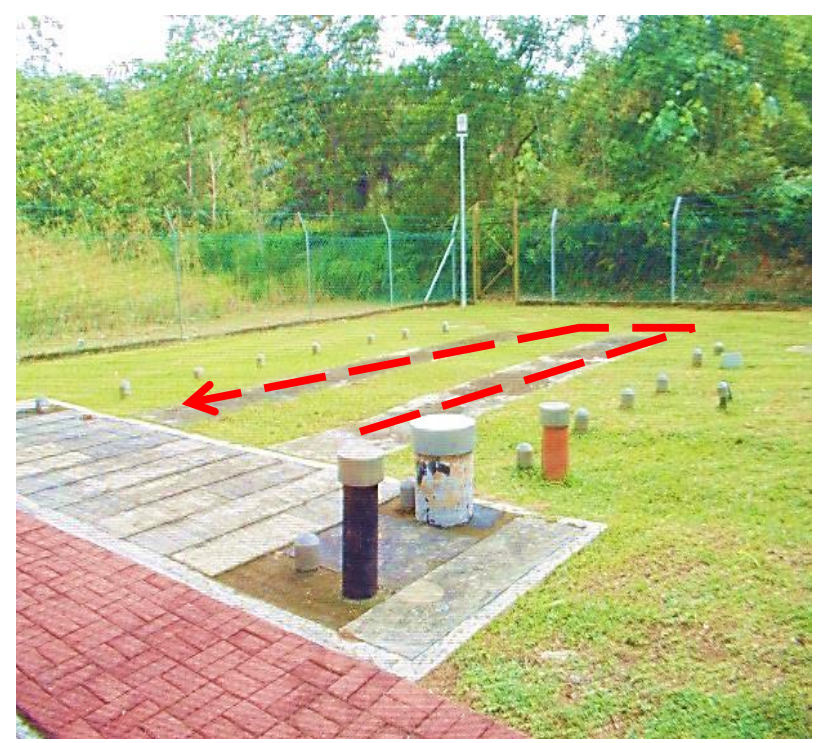

Figure 2. Utility mapping calibration area

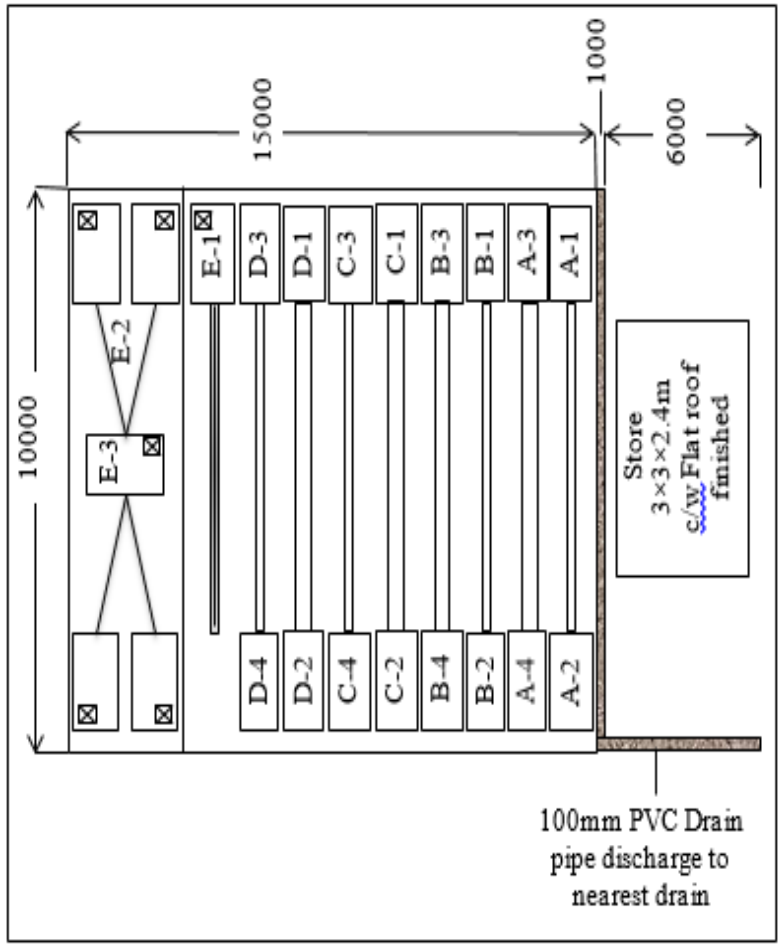

Figure 3. Plan view of the test base

\begin{tabular}{|c|c|c|c|c|}
\hline BII & No & $\begin{array}{c}\text { UTILITY } \\
\text { TYPE }\end{array}$ & MATERIAL & $\begin{array}{c}\text { DEPTH } \\
\text { (METER) }\end{array}$ \\
\hline \multirow[t]{4}{*}{1.} & A-1 & \multirow{4}{*}{$\begin{array}{l}\text { Water } \\
\text { Reticulation } \\
\text { Piping }\end{array}$} & 150mm Ductile Iron Pipe & 0.81 \\
\hline & $A-2$ & & $150 \mathrm{~mm}$ Ductile Iron Pipe & 1.04 \\
\hline & $A-3$ & & $300 \mathrm{~mm}$ MS Pipe & 1.50 \\
\hline & $A-4$ & & $300 \mathrm{~mm}$ MS Pipe & 0.86 \\
\hline \multirow[t]{4}{*}{2.} & $\mathrm{~B}-1$ & \multirow{4}{*}{$\begin{array}{l}\text { Sewerage } \\
\text { Piping }\end{array}$} & $150 \mathrm{~mm}$ V.CP Pipe d/w Copper Stripe & 1.94 \\
\hline & $\overline{B-2}$ & & $150 \mathrm{~mm}$ V.CP Pipe $/ \mathrm{w}$ Copper Stripe & 1.64 \\
\hline & $\mathrm{B}-3$ & & $255 \mathrm{~mm}$ VCP Pipe c/w Copper Stripe & 1.43 \\
\hline & B-4 & & $255 \mathrm{~mm}$ V.CP Pipe c/w Copper Stripe & 1.93 \\
\hline \multirow[t]{4}{*}{3.} & $c-1$ & \multirow[t]{4}{*}{$\begin{array}{l}\text { Electrical } \\
\text { Cable }\end{array}$} & $\begin{array}{l}\text { 240mm 4CPVC/SWAPVC Armour } \\
\text { Cable }\end{array}$ & 1.31 \\
\hline & $c-2$ & & $\begin{array}{l}240 \mathrm{~mm} \text { 4CPVC/SWAPVC Amour } \\
\text { Cable }\end{array}$ & 1.45 \\
\hline & $c-3$ & & $\begin{array}{l}\text { 90mm 4CPVCSWAPVC AMmour } \\
\text { Cable }\end{array}$ & 1.57 \\
\hline & $c-4$ & & $\begin{array}{l}90 \mathrm{~mm} \text { 4CPVCSWWAPVC Armour } \\
\text { Cable }\end{array}$ & 1.42 \\
\hline \multirow[t]{4}{*}{4.} & $D-1$ & \multirow[t]{4}{*}{ Gas Piping } & 180mm HDPE Pipe c w Cable Tracer & 1.48 \\
\hline & $\mathrm{D}-2$ & & 180mm HDPE Pipe c w Cable Tracer & 1.49 \\
\hline & $D-3$ & & 150mm HDPE Pipe c/w Cable Tracer & 1.23 \\
\hline & $\mathrm{D}-4$ & & 150mm HDPE Pipe c w Cable Tracer & 1.49 \\
\hline \multirow[t]{3}{*}{5.} & E-1 & \multirow{3}{*}{$\begin{array}{l}\text { Manhole \& } \\
\text { Telephone } \\
\text { Piping }\end{array}$} & $\begin{array}{l}100 \mathrm{~mm} \text { UPVC Telephone } \mathrm{CW} \\
25 \mathrm{~mm} \text { UPVC sub duct }\end{array}$ & \\
\hline & $\mathrm{E}-2$ & & $100 \mathrm{~mm}$ UPVC Telephone $\mathrm{CW}$ & \\
\hline & $\mathrm{E}-3$ & & $25 \mathrm{~mm}$ UPVC sub duct & \\
\hline
\end{tabular}

Table 1. Detail of utility planted at the calibration area

\subsection{Data Collection}

Fundamentally, data collection is an important part in this study. The equipment must be surely in good condition and work well during data collection. The suitable area for the data collection is identified within UTM. The selected site was located in Universiti Teknologi Malaysia campus, as shown in the unscaled diagram, Figure 4, The site survey is marked with a box.

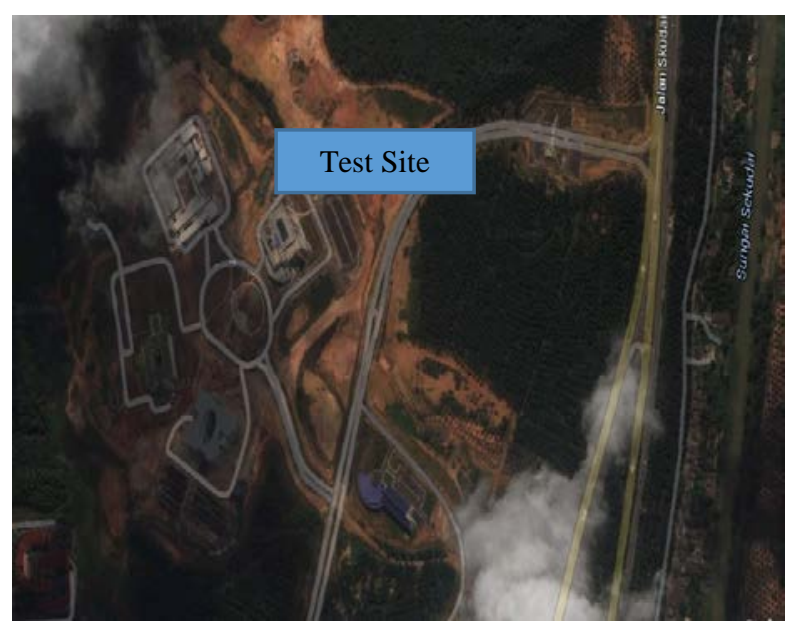

Figure 4.Site Location (Source: Google Map, 2014) 
In order to attain the goal of this study, , test on GPR has been conducted in two conditions; during normal and when leakage was simulated. . The observation was carried out after the pipe is safely planted in the ground. Figure 5 shows the schematic diagram of the test bed. The schematic diagram of the test bed is prepared. (See Figure 5). The site dimension used in this study is $5.6 \times 2.4 \times 0.4 \mathrm{~m}$. meanwhile the pipe dimension is $0.72 \times 0.006 \mathrm{~m}$. A 40 gallon volume of tank is used to run through the pipe. Figure 6 shows picture of the pipe leakage simulation.

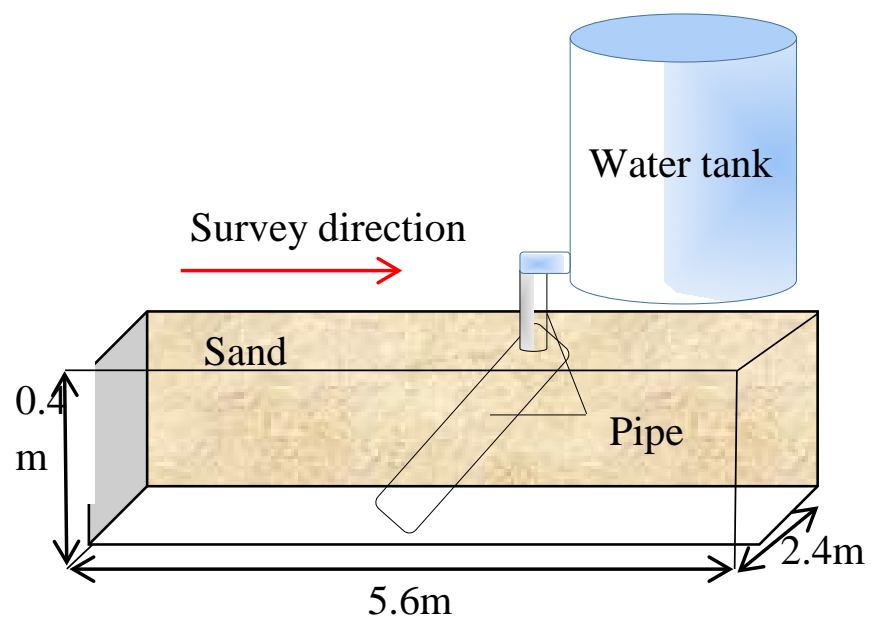

Figure 5. Schematic diagram of the test bed

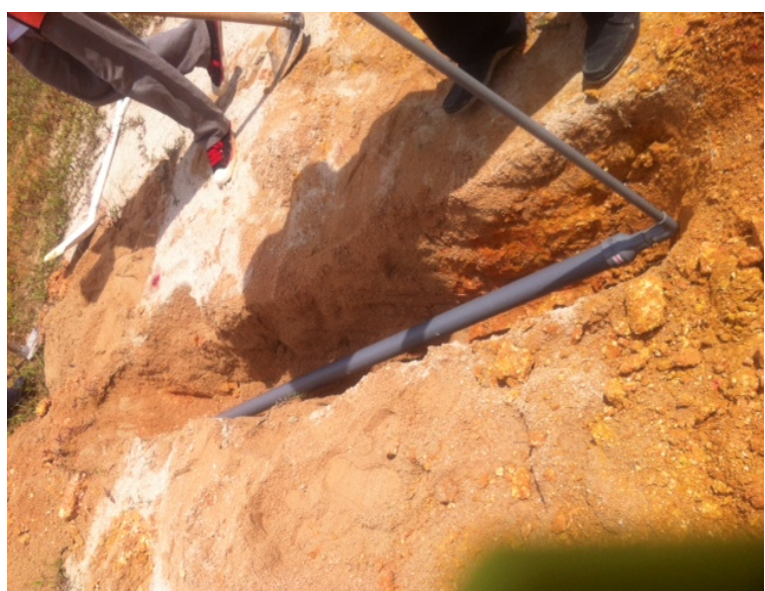

Figure 6. Pipe Leakage Test Bed

The data for these tests were collected using IDS Duo GPR with dual frequency antenna of 250 and 700Mhz. Prior to its used, the instrument was calibrated by moving it. The installed software will spontaneously calibrate the equipment and give the right parameter.

Two different tests were conducted with respect to pipe condition i.e. the normal and simulated leakage condition. Data were scanned at a step of $0.1 \mathrm{~m}$, with a grid of $0.5 \mathrm{~m}$, for longitudinal and transversal, respectively.

Suitable antenna frequency was used for approximate depth range. Thus, deep objects must be larger in diameter than shallow objects. Data processing was done by using Reflex $2 \mathrm{D}$ to derive the image's parameter. Figure 7 shows the radargram image in the Reflex 2D software.

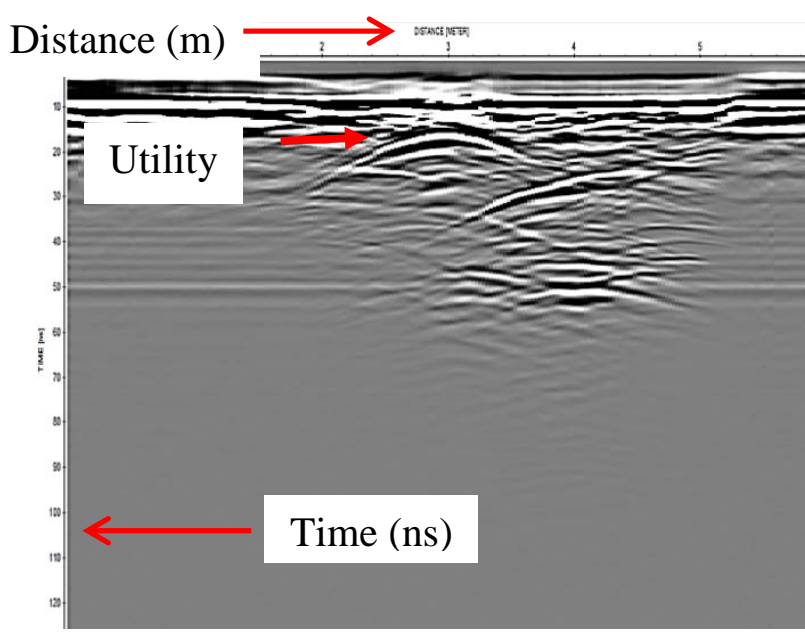

Figure 7. Radargram image

\section{RESULT AND ANALYSIS}

This section presents results and analysis to determine soil moisture content of sand, accuracy of GPS and anomalies in the images in the water leaks test. .To facilitate, the interpretation of radargram, image filtering was applied to reduce noise and extract useful information by improving the visual quality. For example, increase brightness, contrast, and add variety of textures, tones and effects to an image..

\subsection{Soil Compaction}

Principally, soil compaction is a densification of soil particles without outflow of water but with moisture changing by application of mechanic energy. It is necessary to understand the compaction procedure and moisturedensity relations in order to comprehend the environmental influence on soil compaction in the field, such as road trajectory. The test was based on British Standard test method 1377: Part 4: 1990: 3.3/3.4/3.5/3.6. The basic requirement of the test is as follow; volume of mould $(\mathrm{V})=$

$1.000 \mathrm{E}-03_{m^{3}}$

, $2.5 \mathrm{~kg}$ hand rammer and 3 layers of mould with 27 blows per layer. $5 \mathrm{~kg}$ sand sample is used in this testing. Table 2 presents a summary of all data obtained from the soil compaction procedure as directed in section 2 . By using Table 2, a graph is plotted as in Figure 8 below. In addition, Table 2 shows electric constant through various media (Davis and Annan, 1989), used as a comparison of moisture content between sand and other soils. 


\begin{tabular}{|l|c|c|c|c|c|}
\hline Initial sample mass & $\mathrm{g}$ & \multicolumn{5}{|c|}{ Relative density 2.65} \\
\hline $\begin{array}{l}\text { Retained on } 20 \mathrm{~mm} / \mathbf{3 7 . 5} \mathrm{mm} \\
\text { sieve }\end{array}$ & $\mathrm{g}$ & \multicolumn{4}{|l|}{} \\
\hline Test Number & & 1 & 2 & 3 & 4 \\
\hline $\begin{array}{l}\text { Mass of mould + base + } \\
\text { compacted specimen }\left(m_{2}\right)\end{array}$ & $\mathrm{g}$ & 6930 & 7030 & 7050 & 7060 \\
\hline Mass of mould + base $\left.\left(m_{1}\right)\right)$ & $\mathrm{g}$ & 5250 & 5250 & 5250 & 5250 \\
\hline $\begin{array}{l}\text { Mass of compacted specimen } \\
\left(m_{2}-m_{1}\right)\end{array}$ & $\mathrm{g}$ & 1680 & 1780 & 1800 & 1810 \\
\hline $\begin{array}{l}\text { Bulk Density } \\
\text { p = } m_{2}-m_{1} / \mathrm{V}\end{array}$ & $\mathrm{Mg} / \mathrm{m}^{3}$ & 1.680 & 1.780 & 1.800 & 1.810 \\
\hline $\begin{array}{l}\text { Moisture content container } \mathrm{N} 0 \\
\text { Mass of moisture (w) }\end{array}$ & $\%$ & 2.00 & 4.00 & 6.00 & 8.00 \\
\hline $\begin{array}{l}\text { Dry Density } \\
p_{d}=100 p / 100+w\end{array}$ & $\mathrm{Mg} / \mathrm{m}^{2}$ & 1.65 & 1.71 & 1.70 & 1.68 \\
\hline
\end{tabular}

Table 2. Result of soil compaction

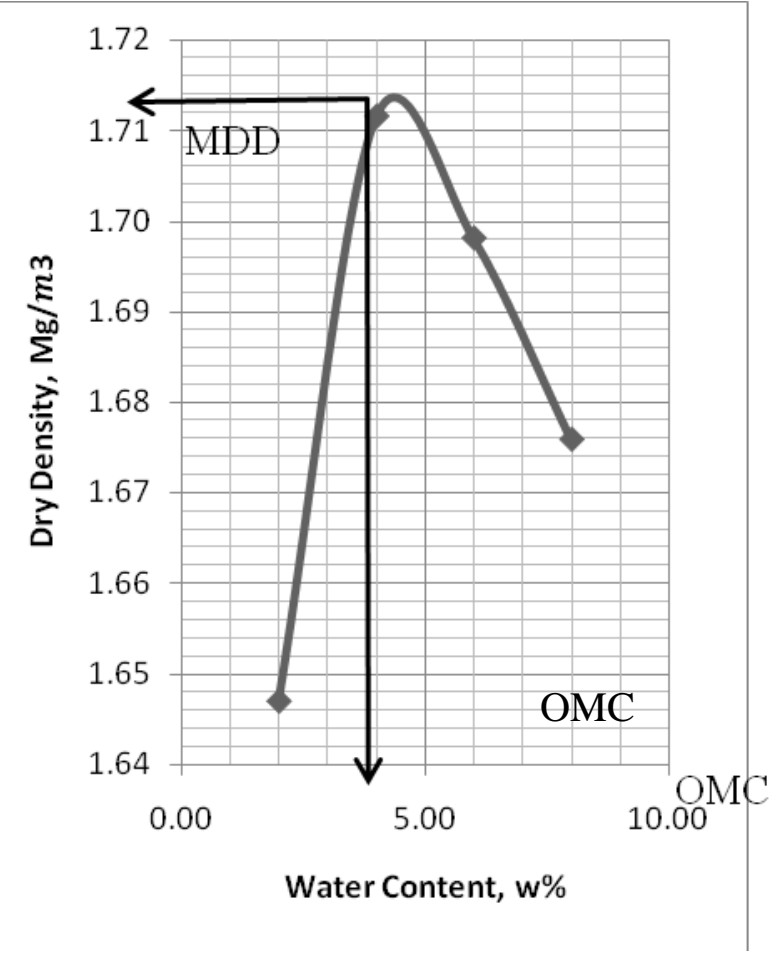

Figure 8. Relationship of dry density and moisture content

This purpose of this test is to determine the relationship between dry density and moisture content through a test on soil specimen by compaction method. Based on Table 2, the relative density of soil used is $2.65 \mathrm{~mm}$ in four experimental tests with different mass of moisture. The compaction curve is plotted as dry density, $\mathrm{Mg} / \mathrm{m}^{3}$ versus water content, w\% as shown in Figure 8. Information obtained from these experiments indicates that the maximum dry unit weight arises as the compaction effort increases because water lubricates the soil element making compaction easier.

Through the graph, the peak of the curve is the soil maximum dry density (MDD) $1.714 \mathrm{Mg} / \mathrm{m}^{3}$, meanwhile the optimum moisture content (OMC) is $4.5 \%$. In general, the conditions may be more adverse than this because the dry density would arise when the moisture content increase. The most stable density-strength is shown by sample with its higher moisture content. However, the optimum moisture content declines to some level when extra water is added where the water content is larger than the optimum value. Thus, the void space is filled with water, so further compaction is not possible because water is an incompressible fluid.

\begin{tabular}{|l|c|}
\hline \multicolumn{1}{|c|}{ Material } & Dielectric Constant \\
\hline Air & 1 \\
\hline Fresh water & 80 \\
\hline Limestone & $4-8$ \\
\hline Shale & $5-15$ \\
\hline Dry sand & $3-5$ \\
\hline Clay & $4-40$ \\
\hline Silt & $5-30$ \\
\hline
\end{tabular}

Table 3. Dielectric constant through various media (Davis and Annan, 1989)

Meanwhile, Table 3 shows electric constant through various media (Davis and Annan, 1989). The table is used to compare the dielectric constant of other materials or soils, that also explained the used of sand in this study. Water is a polar molecule. Water molecules experience a force that acts to align their permanent dipole moments parallel to the direction of the applied electrical field when an alternating electrical field is applied to the soil (Daniels, 2004). The electrical conductivity of soils upsurges with increasing water, soluble salt, or clay content (McNeil, 1980). These soil properties determine electrical charge carriage and storage (Olhoeft, 1998).

- The high adsorptive capacity of water, other soils increase the dissipation of electromagnetic energy than sand. Through soil compaction, it was proved that sand has low optimum water content. A study of Figure 8, Table 2 and comparison in Table 3 discloses that characteristic of maximum and minimum density limits exist for granular soil, sand which is determined by the amount of water in the soil. The dry density can be achieved depends on the degree of compaction applied and amount of water present in the soil 


\subsection{GPR Calibration}

Table 4 shows the details obtained from the estimated pipes' location.

The red lines in the Figure 4 indicate the estimated location for some of the pipes based on the distance of the pipes in the area. However, it is a poor radargram with attenuated signal from highly conductive soil. The GPR observation has been conducted after raining day as rain could change the dielectric constant in soil. It might also because of the error during setting up the equipment. In this study, the dissimilar bouncing of electromagnetic waves at the image shows different types of pipe with diverse depth planted in the ground. The emitted waves contain varies elements of electricity, mainly the properties of dielectric and conductive constituents, magnetic permeability and physical properties of the object such as size, shape, depth and conductivity of the target.

The relative permittivity varies greatly with water content in the medium. Water contain is the major factor that determines the relative dielectric permittivity of a geological material. The relative dielectric permittivity of a material decides the velocity of the GPR signal and how the signal is spread in the medium. A suitable antenna frequency is used for approximate depth range. In fact, deep objects must be larger in diameter than shallow objects. However, different types of pipe might be a new research topic as user could learn to differentiate the signal.

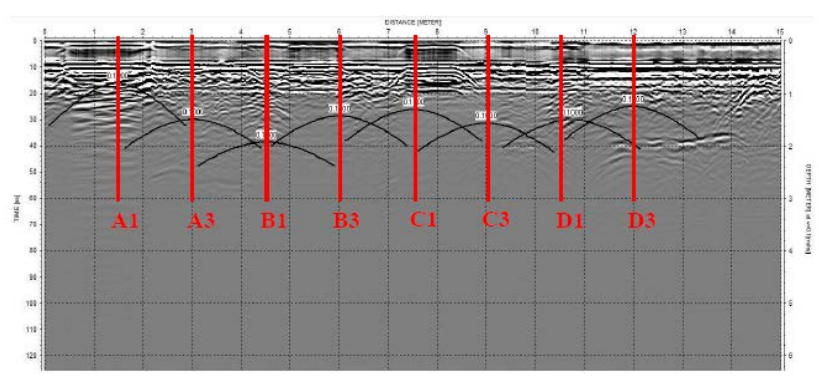

Figure 9. GPR calibration result

\begin{tabular}{|c|c|c|c|c|c|}
\hline $\begin{array}{c}\text { Pipe } \\
\text { No. }\end{array}$ & $\begin{array}{c}\text { Actual } \\
\text { Depth (m) }\end{array}$ & $\begin{array}{c}\text { Estimated } \\
\text { Depth (m) }\end{array}$ & $\begin{array}{c}\text { Time } \\
(\mathbf{n s})\end{array}$ & $\begin{array}{c}\text { Amplitude } \\
(\boldsymbol{A})\end{array}$ & $\begin{array}{c}\text { Velocity } \\
\left(\frac{\mathbf{m}}{\boldsymbol{n}}\right)\end{array}$ \\
\hline A1 & 0.81 & 0.8125 & 16.25 & 231.1960 & 0.05 \\
\hline A3 & 1.50 & 1.5000 & 30.00 & 2.7954 & 0.05 \\
\hline B1 & 1.94 & 1.9375 & 38.75 & 1.9686 & 0.05 \\
\hline B3 & 1.43 & 1.4375 & 28.75 & 2.3160 & 0.05 \\
\hline C1 & 1.31 & 1.3125 & 26.25 & 16.2170 & 0.05 \\
\hline C3 & 1.57 & 1.5750 & 31.50 & 2.5457 & 0.05 \\
\hline D1 & 1.48 & 1.4870 & 29.75 & 123.2980 & 0.05 \\
\hline D3 & 1.23 & 1.2375 & 24.75 & 41.9580 & 0.05 \\
\hline
\end{tabular}

Table 4. Details obtained from the estimated pipes’ location

\subsection{Pipe Leakage Simulation}

As mentioned in the preceding section, two tests have been conducted with regard to water pipe leakage detection. Figure 10 and 11 show the results of the test.

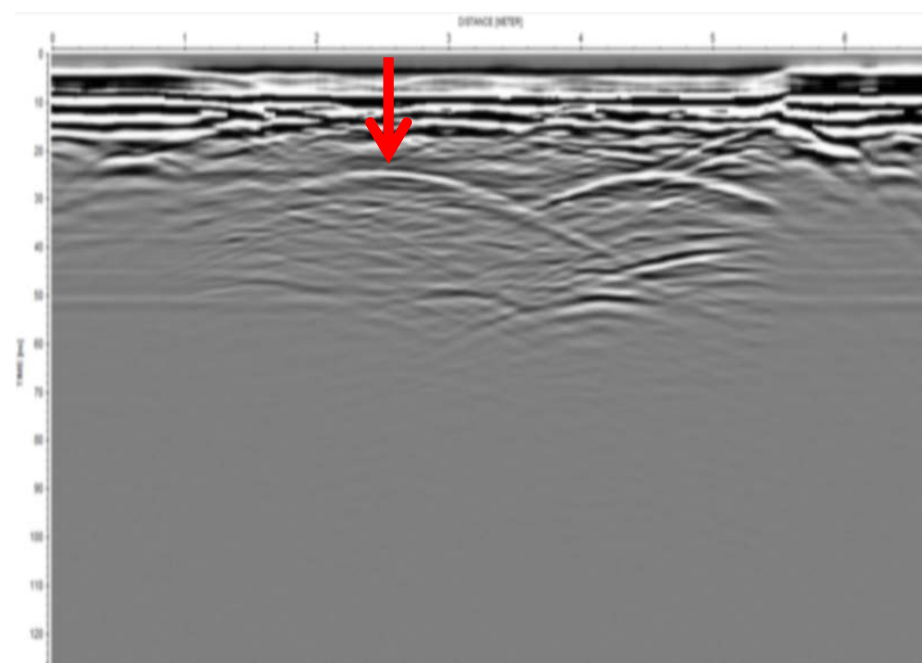

Figure 10. Image of good pipe condition

Figure 10 shows the normal pipe condition (dry sand) as marked with arrow. From the Figure 9, it shows that there are many pipes underneath the ground. It is because the experiment is conducted at an abandoned used area. The area has been abandoned for one year and no other activity is done during the period. It was a selected site as the author needs to get permission to do the experiment within UTM campus.

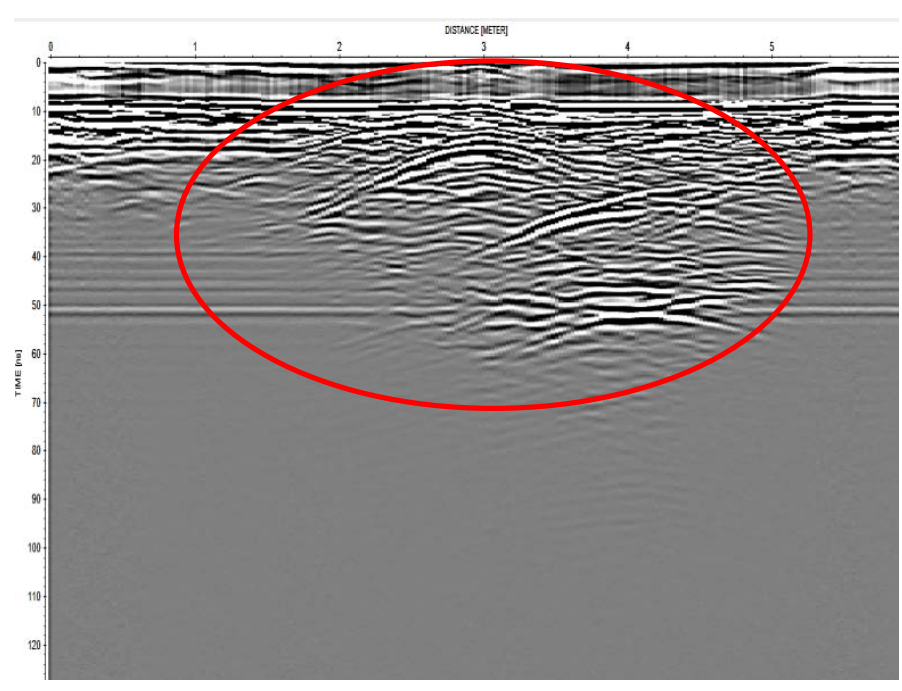

Figure 11. Image of water leakage

Meanwhile, Figure 11 shows the image of the water leakage. The black area circle with red in the image shows that the water is cumulated under the ground before bursting on ground. The water did not bursting on ground during simulation might because of the low pressure during water transfer from the tank to the pipe. Thus, new research 
on water pressure effect should be done in future study. Result obtained from Figure 10 is related to Figure 9 as there are dielectric changes caused by water. Note that the water content is mainly causes some alterations in soil's dielectric properties. Soils which contain adequate water have higher penetration than dry soil. Anomalous changes to sand from electromagnetic reflection due to water leakage in this study are justified to another test performed by Eyuboglu et.a. (2015) and Ayala-Cabrera et.al.,(2014)

Penetration of water is $80 \mathrm{~m}$. In geological material, water is the most significant factor in directing the electrical properties in terms of conductivity within penetration depth and relative dielectric permittivity for velocity of signal. However, based on Mala and RD-Palmer note, (2008), (http://www.malags.com), when the conductivity of a geological medium is more than $10 \mathrm{mS} / \mathrm{m}$ or less than 100 $\mathrm{Ohm} / \mathrm{m}$, GPR might not be suitable for surveys in that area. The finding from this study indicates that GPR could be one of best equipment use in detecting water leakage without excessive ground digging and the result would appear in real time. The image occurred in real time and the ground could be mark directly during survey. Besides, GPR is equipped with dual frequency which could be used for various purposes.

\section{CONCLUSION}

The aim of this paper was to detect fluid leakage using GPR. The aims have led to three objectives used in this study. The first objective is to retrieve the soil moisture. It is well known that water content in the sediment is primarily because of some changes in the soil's dielectric constant. Hence, the geophysical properties of the sand have been proved through soil compaction. Soil compaction is used to detect the MDD of the sand and confirm the use of sand in pipe buried application in Malaysia. The second objective was to evaluate the performance of GPR in water leakage detecting. Through this study, the strength and limitation of GPR in pipe leakage detection was identified. Consequently, the use of GPR could improve the time period to monitor and detect pipe leakage in real time through GPR radargram. It is a very practical and effective way to provide precise utility location of the problematic area without digging the ground. Finally, GPR has proved to be as the non-destructive method that helps to locate early leaks and avoid additional damages by providing precaution and awareness to the community.

The final objective of this paper was to visually differentiate images between two pipe conditions. By appropriate processing methodology with the processing software has facilitates the visualization of contaminated soil which is not reflected in the raw images. Consequently, the use of GPR should be considered for educational and scientific studies. In addition, it would also profit the authorities in several aspects such as contributing an updated record and safety of water supply network. The tests on GPR performance have shown that it is capable of supporting utility positioning activities.

Nevertheless, further studies are recommended to explore the capabilities of the GPR in this subject. This study has performed on sand; hence, it is suggested to conduct GPR observation on different types of soil as soil has diverse electromagnetic properties such as clay and peat soil. The molecule, salinity and other factor of soil are totally different. Also to compare the performance of electromagnetic GPR in fluid leakage detection with other methods such as acoustic methods.

\section{ACKNOWLEDGEMENT}

The authors gratefully acknowledge the Ministry of Education and Universiti Teknologi Malaysia for their kind financial support (Vot No.: R.J130000.7827.4F467).

\section{REFERENCES}

A. J. Cotte, Weili Ma, M.R. Rayner and C.G. Parini (2003). Application of the DGF-FDTD Technique to Log Periodic Antennas. The Institute of Electrical Engineers. IEEE paper.

Annan AP (2005). Ground Penetrating Radar. In Near Surface Geophysics, Butler

DK (Ed). Society of Exploration Geophysicists: Tulsa, Investigations in Geophysics 13; 357-438.

Ayala-Cabrera D., Campbell E., Carreno-Alvarado E.P., Izqueirdo J. and Perez-Garcia R.(2014). Water Leakage Evolution Based on GPR Interpretations, Procedia Engineering 89, 304-310.

Behari, J., (2005). Measurement of Water Content. Remote Sensing and Digital

Image Processing. (pp.41-65). New Delhi, India: Anamaya.

Bose J. R. (1993). TAPS’s Leak Detection Seeks Greater Precision. Oil and Gas

Journal. April 5. Pg. 43-47.

Booth, A. R., (1976). Compaction and Preparation of Soil Specimens for Oedometer Testing. Soil Specimen Preparation for Laboratory Testing. Seventy-eighth Annual Meeting Symposium. Montreal, Canada, 22-27 June 1975. ASTM STP 599, American Society for Testing and Materials, 1976, pp. 216-228.

Brady, N. C., and R. R. Weil. (2008). The Nature And Properties of Soils. 14th

Edition Pearson-Prentice Hall, Upper Saddle River, NJ.

Chadwell M. G. (2007). Environmental Protection Division. Water Leak Detection and Repair Program. Georgia Environmental Protection Division: Watershed Protection Branch.

Chu, T. Y. and Chen, S. N. (1976). Laboratory Preparation of Specimens for Simulating Field Moisture Conditions of Partially Saturated Soils. Soil Specimen Preparation for Laboratory Testing. Seventy-eighth Annual Meeting Symposium. Montreal, Canada, 22-27 June 1975. ASTM STP 599, American Society for Testing and Materials, 1976, pp. 229-247.

Daniels, D.J. (2004). Ground Penetrating Radar. (2nd ed). The Institute of Electrical

Engineers, London, United Kingdom.

Dahlia Rosly (2012). Sustainable Development: An Overview. Advancing the Sustainable Development 
Agenda through Aligning Malaysia Plans \& Policies. National Consultation Workshop United Nation Conference on Sustainable Development 2012. Federal Department Of Town and Country Planning. Oct 8, 2011.

Evans R. D. (2009). Optimizing Ground Penetrating Radar (GPR) to Assess

Pavements. Doctor of Engineering. Loughborough University.

Eyuboglu S., Mahdi H. and Al-Shukri H, April 13, 2015. Detection of Weak Leaks Using Ground Penetrating Radar, www.dot.state.fl.us/statemasterialsoffice/geotechnical/confe rence/materials/eyuboglu-mahdi-alshukri.pdf

MP: MRT Project Cost up by Another RM172m due to Utility damage.

March 17, 2014. www.fz.com/content/mp-mrt-project-costanother-rm172m-due-utility-damage

Mohd Shahir bin Yaman (2014). Extraction of Soil Stratigraphy in Ground

Penetrating Radar (GPR) Data. Master Thesis. Universiti Teknologi Malaysia.

Olhoelf, G. R. (1998). Electrical, Magnetic and Geometric Properties That

Determine Ground Penetrating Radar Performance. Proceedings, Seventh International Conference on Ground Penetrating Radar. May 27-30, 1998. University Of Kansas, Lawrence, Kansas, USA. Pp. 177-182.

Parry B., Mactaggart R., Toerper C. (1992). Compensated Volume Balance Leak

Detection on a Batched LPG Pipeline. Proceedings of Offshore Mechanics \& Arctic Engineering Conference (OMAE).

Reddy K. (2002). Experiment 9 Moisture-Density Relation (Compaction) Test.

Engineering Properties of Soil Based on Laboratory Testing. UIC

The Star: PJ Folk May Experience Dry Taps due to Burst Pipe. Feb, 162014.

news.asiaone.com/news/Malaysia/pj-folk-may-experiencedry-taps-due-burst-pipe

Saarenketo, T. and Scullion, T. (2000). Road Evaluation with Ground Penetrating

Radar. Journal of Applied Geophisics, 43, pp 119-138.

Sandmeier geophysical software. (2014). Reflex 2D-Quick guide. Karlsruhe, Germany. (Downloaded from: http:// www.)

The Star: Piling Works Rupture Water Mains Pipe along Federal Highway. Match 15, 2014. www.thestar.com.my/News/Nation/2014/03/15/burst-pipefed-hway/

The Star: Outdated Utility Maps Reason for Water Cuts, says MRT Corp. September

30,2013.

www.thestar.com.my/News/Community/2013/09/30/Outdat

ed-utiity-maps-reason-for-water-cuts-says-MRT-

Corps.aspx/
Turner N. C. (1991). Hardware and Software Techniques for Pipeline Integrity and

Leak Detection Monitoring. Proceedings of Offshore Europe 91. Aberdeen, Scotland.

Utility Location. Available at http://www.naevageophysics.com/UtilityLocation

Weil G.J. (1993). Non-Contact, Remote Sensing Of Buried Water Pipeline Leaks

Using Infrared Thermography. Water Resources Planning and Management and Urban Water Resources, Pg. 404-407.

Zhang D. (2012). Measurement of Soil Water Content Using Ground Penetrating

Radar. Master Thesis. Royal Institute of Technology.

Zhang J. (1996). Designing a Cost Effective and Reliable Pipeline Leak Detection

System. Pipeline Reliability Conference, Houston, USA, November 19-22, 1996. 